\title{
Accidental iohexol bronchography
}

\author{
Lokesh Koumar Sivanandam, Rohan Jacob Verghese, Shiva Balan (1) , \\ Kandan Balamurugesan
}

Medicine, Jawaharlal Institute of Postgraduate Medical Education and Research, Puducherry, India

\section{Correspondence to Dr Kandan Balamurugesan; pkbala77@gmail.com}

Accepted 21 July 2021
Check for updates

(c) BMJ Publishing Group Limited 2021. No commercial re-use. See rights and permissions. Published by BMJ.

To cite: Sivanandam LK, Verghese RJ, Balan S, et al. BMJ Case Rep

2021:14:e244942.

doi:10.1136/bcr-2021-

244942

\section{DESCRIPTION}

A 43 -year-old woman underwent a video fluoroscopic swallowing study as a part of evaluation for dysphagia during which $10 \mathrm{~mL}$ of iohexol (Omnipaque) was given as a contrast medium. As the patient aspirated some of the contrast medium, the procedure was abandoned immediately. She maintained an arterial oxygen saturation of $95 \%$ in room air. Chest radiographs showed tracking of the contrast along the bronchi of both lower lobes showing a classical 'bronchography' (figure 1A). The patient was treated with intravenous piperacillin + tazobactam and clindamycin for aspiration pneumonia and chest physiotherapy. She was discharged after 7 days with no symptoms. At follow-up 2 weeks later, she was doing well with a repeat chest radiograph showing clearance of the radiocontrast deposits (figure 1B) and contrast-enhanced CT imaging of the lungs revealing residual contrast deposition in the distal bronchi of both lower lobes (figure 1C).

Oral contrast agents are used for studies of the gastrointestinal tract such as pharyngography, esophagography, upper gastrointestinal studies and small-bowel follow-through examinations. The two categories of contrast used in such studies are barium sulfate suspensions and watersoluble iodinated contrast media. The watersoluble contrast media are divided into two types: high-osmolar contrast media (HOCM) and low-osmolar contrast media (LOCM). The two currently available HOCMs are Gastrografin and Gastroview. LOCMs are generally supplied for intravenous use, and their use in oral contrast studies is considered 'off label' apart from iohexol (Omnipaque), which has US Food and Drug Administration approval for the same. ${ }^{1}$

Aspiration of contrast medium is a common complication of oral contrast fluoroscopy and is seen in up to $22 \%$ of fluoroscopic examinations. ${ }^{2}$ Such aspiration occurs more frequently in children and is associated with serious adverse reactions such as chemical pneumonitis and acute respiratory distress syndrome. These adverse reactions are especially prominent in HOCM, in which the high osmolality draws water into the alveoli, resulting in pulmonary oedema. ${ }^{1}$ Barium sulfate, in comparison, is relatively inert and is cleared by the alveolar cilia. However, in lungs with damaged epithelium, it can accumulate and cause pneumonitis and fibrosis. ${ }^{1}$ Iohexol has an osmolality of around $322 \mathrm{mOsm} / \mathrm{kg}$, which is comparable to plasma. This, coupled with its chemically inert nature, and water solubility

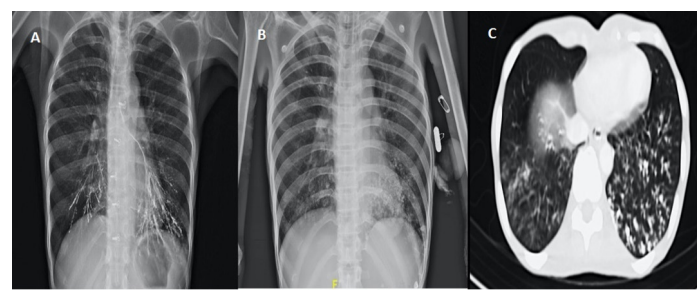

Figure 1 (A) Chest radiograph postcontrast swallow showing tracking of contrast along bilateral lower lobe bronchi. (B) Follow-up chest radiograph done 2 weeks later showing clearance of radiocontrast deposits. (C) Axial contrast-enhanced CT showing multiple centrilobular nodules in bibasal segments with 'tree in bud' appearance, showing high attenuation in the range of iodinated contrast.

reduce the risk of contrast-induced pneumonitis. ${ }^{3}$ In addition, the taste of iohexol and other LOCMs is considered more palatable, making them the preferred agents in aspiration-prone patients. ${ }^{1}$

The management of oral contrast aspiration is usually conservative; however, severe cases may require oxygen support or intubation and mechanical ventilation. There are no standard guidelines for treating oral contrast aspiration and no data regarding the use of antibiotics in such aspiration. It is prudent that every radiology department has a mechanism for evaluating and treating this contrast-related adverse event. This case is being reported for its classical image of 'bronchography' in chest radiograph following aspiration of a small amount of LOCM iohexol during the video fluoroscopic swallowing study for the evaluation of dysphagia. Our patient had complete recovery with symptomatic treatment. Earlier recognition of this adverse event and

\section{Learning points}

Oral contrast fluoroscopic studies carry a significant risk of aspiration, and the contrast medium can be seen in a chest radiograph as radio-opaque deposits along the bronchial wall.

- Early recognition of this adverse event and appropriate imaging is key in the management of such aspiration.

- Aspiration of iohexol is associated with less acute as well as long-term sequalae as compared with barium sulfate and Gastrografin, making it the preferred agent in patients at risk of aspiration. 
obtaining appropriate imaging is critical in successful treatment of the patient.

Contributors LKS contributed to the case assessment, management and collection of case images. KB contributed to the conceptualisation and literature review. SB analysed and interpreted the patient details and data. RJV contributed to writing and editing the manuscript. All the authors read and approved the final manuscript.

Funding The authors have not declared a specific grant for this research from any funding agency in the public, commercial or not-for-profit sectors.

Competing interests None declared.

Patient consent for publication Obtained.
Provenance and peer review Not commissioned; externally peer reviewed.

\section{ORCID iDs}

Shiva Balan http://orcid.org/0000-0003-3427-490X

Kandan Balamurugesan http://orcid.org/0000-0001-7756-0565

\section{REFERENCES}

1 Federle MP, Jaffe TA, Davis PL, et al. Contrast media for fluoroscopic examinations of the Gi and GU tracts: current challenges and recommendations. Abdom Radiol 2017:42:90-100.

2 Claussen D. Omnipaque (iohexol). Gastroenterol Nurs 1992:14:307-9.

3 Harris JA, Bartelt D, Campion M, et al. The use of low-osmolar water-soluble contrast in videofluoroscopic swallowing exams. Dysphagia 2013;28:520-7.

Copyright 2021 BMJ Publishing Group. All rights reserved. For permission to reuse any of this content visit https://www.bmj.com/company/products-services/rights-and-licensing/permissions/

BMJ Case Report Fellows may re-use this article for personal use and teaching without any further permission.

Become a Fellow of BMJ Case Reports today and you can:

- Submit as many cases as you like

- Enjoy fast sympathetic peer review and rapid publication of accepted articles

- Access all the published articles

Re-use any of the published material for personal use and teaching without further permission

Customer Service

If you have any further queries about your subscription, please contact our customer services team on +44 (0) 2071111105 or via email at support@bmj.com.

Visit casereports.bmj.com for more articles like this and to become a Fellow 